\title{
Los sabios del tiempo axial
}

A mediados del siglo $\mathrm{V}$ antes de Cristo un número creciente de seres humanos comenzó a sentir que las prácticas espirituales de sus antepasados habían dejado de funcionar para ellos. Este desasosiego afectó a individuos del mundo civilizado de regiones muy distantes entre sí, y desembocó en cambios fundamentales para la humanidad.

En su obra "Origen y meta de la historia", el médico psiquiatra y filósofo existencialista Karl Jaspers denomina a esta época como el tiempo axial o tiempo eje, y plantea que entre los años 800 y 200 antes de Cristo, se vivió un momento misterioso pero absolutamente real y que ha seguido alimentando a los hombres y mujeres hasta la actualidad. En ese tiempo el hombre se eleva a la conciencia de sí mismo; se formula preguntas radicales, y mientras cobra conciencia de sus límites se propone las finalidades más altas.

Una impresionante formación de genios proféticos y filosóficos hacía denodados esfuerzos por encontrar una solución al vacío percibido.

En China viven Confucio y Lao-tsé, quienes transformaron las tradiciones filosóficas y religiosas. En la India vive y predica Siddharta Gautama, el Buda. En Persia, el sabio iraní Zoroastro enseña la doctrina que presenta al mundo como el combate entre el bien y el mal y es el primero en fundar una religión monoteísta. En Palestina aparecen los profetas hebreos Elías, Isaías y Jeremías, mientras en Grecia encontramos a Sócrates y Platón, Homero, Heráclito y Parménides.

Buda, los profetas hebreos y los filósofos

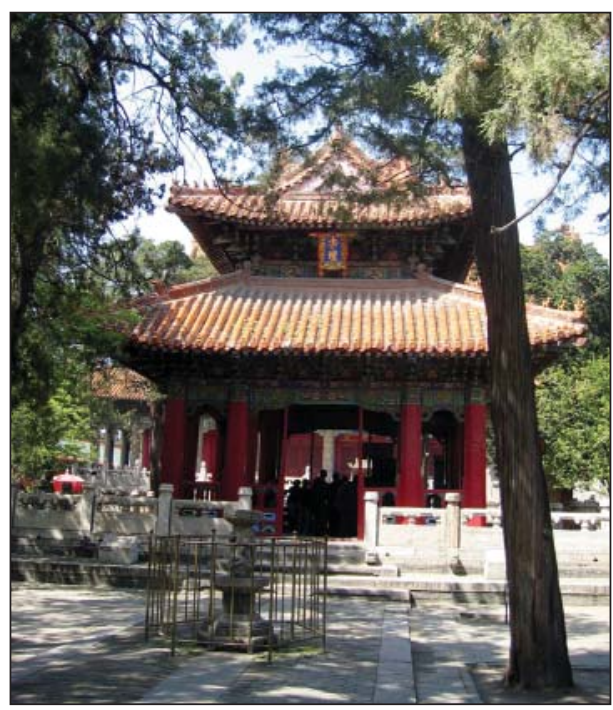

Figura 1. Templo de Confucio en Qufu, Provincia de Shandong, China. Foto por Rolf Müller.
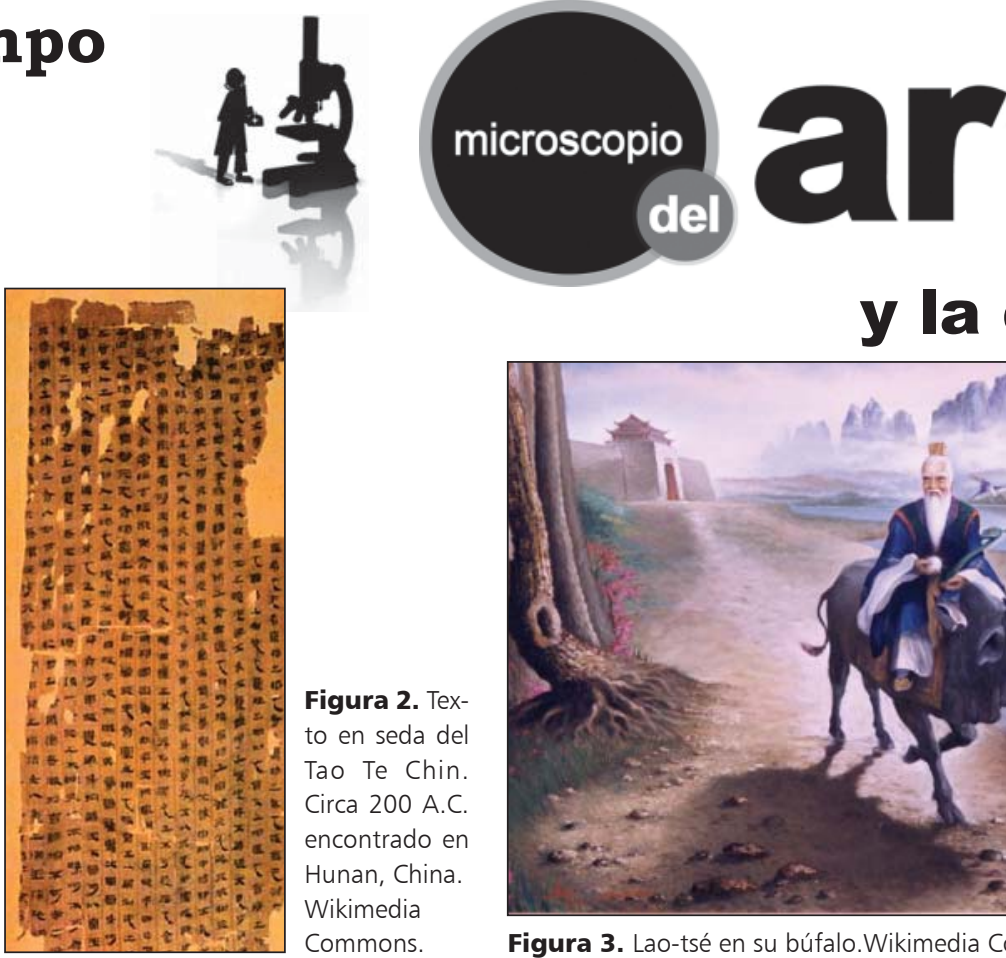

y la cultura

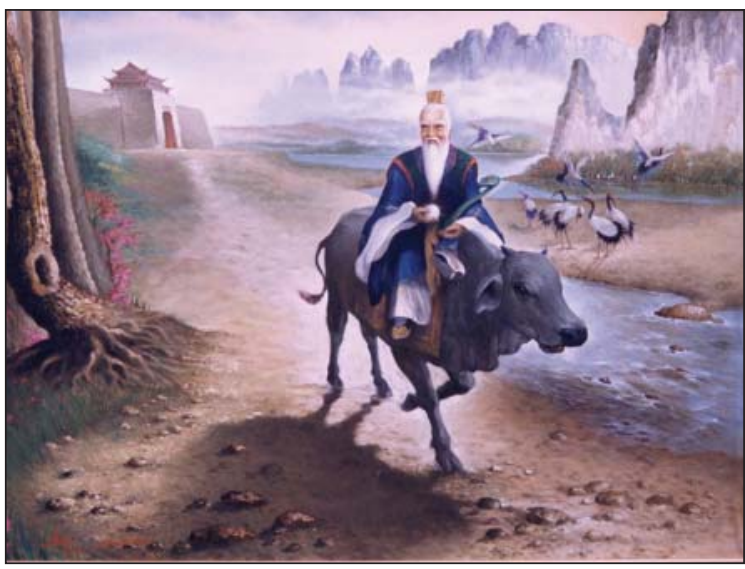

Figura 3. Lao-tsé en su búfalo.Wikimedia Commons. griegos son relativamente conocidos; en cambio Zoroastro, Confucio y Lao-tsé permanecen relativamente desconocidos para los occidentales.

Zoroastro vivió posiblemente hacia el siglo VI antes de Cristo en Irán o Afganistán donde, al igual que Buda en la India, convenció con sus ideas religiosas, las que se extendieron por toda el Asia Central y Occidental. En lo fundamental, establece que el conflicto entre el bien y el mal marca la existencia humana, y promueve el concepto de un Dios único, en contra de las religiones politeístas. $\mathrm{Su}$ influencia persistió hasta la alta edad media, cuando la irrupción del Islam la erradicó casi por completo. Sin embargo, sus tesis religiosas ejercieron una notoria influencia en las religiones monoteístas del cercano oriente como el judaísmo, el cristianismo y el mismo islamismo.

Entretanto, en la lejana China, dos grandes sabios establecían un nuevo rumbo en la filosofía y la religión. Confucio, llamado el maestro Kong, y Lao-tsé fueron contemporáneos y vivieron en el siglo $\mathrm{V}$ antes de Cristo. Confucio fue un filósofo y reformador social más que un hombre de religión y ocupó altos cargos administrativos, llegando a ser ministro. Su filosofía humanista y su ética política así como el sincretismo con el budismo, el taoísmo e incluso el maoísmo marxista, han empapado la conducta del pueblo chino durante más de dos mil años (Figura 1). Al igual que Buda, no propone ningún credo ni culto y es más bien agnóstico en términos religiosos; se consideraba un continuador de las enseñanzas de los sabios antiguos y la esencia de su doctrina era el Zen, que definió como "amar a los hombres". Propugnaba la búsqueda de la perfección moral mediante el cultivo de la sinceridad, la moderación, la justicia, la fidelidad y la lealtad. Estos valores, desarrollados en forma colectiva, permitirían a los hombres conformar una sociedad en armonía. Confucio está enterrado en la ciudad china de Qufu y su casa natal es patrimonio de la humanidad.

Acerca de Lao-tsé, fundador del Taoísmo, se sabe bastante menos, excepto que fue más bien un hombre místico y religioso. Por su sabiduría fue designado conservador de la gran biblioteca imperial, donde llegaba el joven Confucio para mantener con él largas discusiones teológicas y filosóficas.

$\mathrm{Su}$ tesis fundamental es la existencia de un principio rector del universo denominado Tao o camino, y un modo de alcanzarlo denominado $\mathrm{Te}$ o virtud. Se cree que es el autor del texto madre del Taoísmo, el Tao Te Ching y de los conceptos de Yin y Yang como fuerzas complementarias que en constante evolución conforman el Tao u orden natural del universo (Figura 2). El Yin, que significa "la ladera sombría," representa la fuerza concreta, masculina o seca y el Yang o "ladera luminosa" la fuerza sutil, femenina o húmeda, con el Tao como fuerza superior que las contiene.

Se cuenta que luego de permanecer dos años escribiendo el texto, subió a un búfalo y se perdió en dirección al norte, sin que se volviera a tener noticias suyas (Figura 3).

\section{Referencias}

1. Jaspers, Karl. Origen y meta de la historia. 1995; Ediciones Altaya, Barcelona.

2. Enciclopedia Hispánica: Encyclopaedia Britannica Publishers,Inc. Versailles Kentucky, 1994.

Ernesto Payá G. 